\title{
Acute bilateral blindness in a young Covid- 19 patient with rhino-orbito-cerebral mucormycosis
}

\author{
Ines Malek ${ }^{1}$, Jihene Sayadi ${ }^{1 *}$ (D), Rim Lahiani ${ }^{2}$, Miriam Boumediene ${ }^{3}$, Memia Ben Salah $^{2}$, Myriam Jrad ${ }^{3}$, \\ Moncef Khairallah ${ }^{4}$ and Leila Nacef ${ }^{1}$
}

\section{Case report}

A diabetic 20 -year-old male patient, not previously vaccinated against SARS-CoV-2, was referred to our emergency department for rapid bilateral visual loss with left periorbital pain, proptosis, palpebral edema and swelling.

He had been admitted one week before in a primary Covid-19 center for COVID-19 respiratory distress syndrome and treated with corticosteroids.

Upon ophthalmic examination, both eyes had a fixed dilated pupil with no light perception. The left eye showed features of orbital cellulitis (Fig. 1) with complete ophthalmoplegia (Fig. 2). There was a mild proptosis and limited abduction in the right eye (Fig. 2), and fundus examination showed retinal whitening with a cherry red spot and segmental blood flow consistent with central retinal artery occlusion (CRAO) (Fig. 3). Swept source OCT showed in the right eye hyperreflectivity of inner retinal layers corresponding to ischemic edema (Fig. 3).

Brain CT complemented with cerebral MRI disclosed endocranial extension of the disease and thrombosis of both left cavernous sinus and left internal carotid artery (Fig. 1).

The patient underwent emergency endoscopic sinus examination and removal of a blackish necrotic tissues from paranasal sinuses. Histopathological examination confirmed the diagnosis of mucormycosis.
The patient was started on intra-venous liposomal amphotericin B and clavulanic-acid-amoxicillin. Dexamethasone was discontinued. Debridement of the involved sinuses and adjacent structures was attempted together with diluted amphotericin B irrigation. Orbital exenteration was discussed but it was not retained due to poor prognosis and lack of the patient's consent.

Over the following days, the patient's ocular and general conditions worsened due to bilateral extensive eyelid and facial necrosis with purulent melting of the left eyeball and central nervous system involvement (Fig. 4). He passed away at day 30 .

\section{Discussion}

With the onset of COVID-19 pandemic, clinicians have seen a sudden surge of cases of mucormycosis. Although all ocular structures may be involved in patients with COVID-19 infection, orbital mucormycosis seems to be the most aggressive and so far fatal complication [1-3].

To the best of our knowledge very few cases of severe bilateral blindness in Covid-19 patient have been reported [2-6]. They were related either to orbital location of mucormycosis $[2,3]$ or to neurological complications including bilateral optic neuritis [4] and occipital ischemic stroke $[5,6]$.

\footnotetext{
* Correspondence: jihene.sayadi@hotmail.com

${ }^{1}$ A Department Hedi Raies Institute of Ophthalmology, Tunis El-Manar

University, Tunis, Tunisie

Full list of author information is available at the end of the article
}

\section{Springer Open}

(ㅇ The Author(s). 2021 Open Access This article is licensed under a Creative Commons Attribution 4.0 International License, which permits use, sharing, adaptation, distribution and reproduction in any medium or format, as long as you give appropriate credit to the original author(s) and the source, provide a link to the Creative Commons licence, and indicate if changes were made. The images or other third party material in this article are included in the article's Creative Commons licence, unless indicated otherwise in a credit line to the material. If material is not included in the article's Creative Commons licence and your intended use is not permitted by statutory regulation or exceeds the permitted use, you will need to obtain permission directly from the copyright holder. To view a copy of this licence, visit http://creativecommons.org/licenses/by/4.0/. 

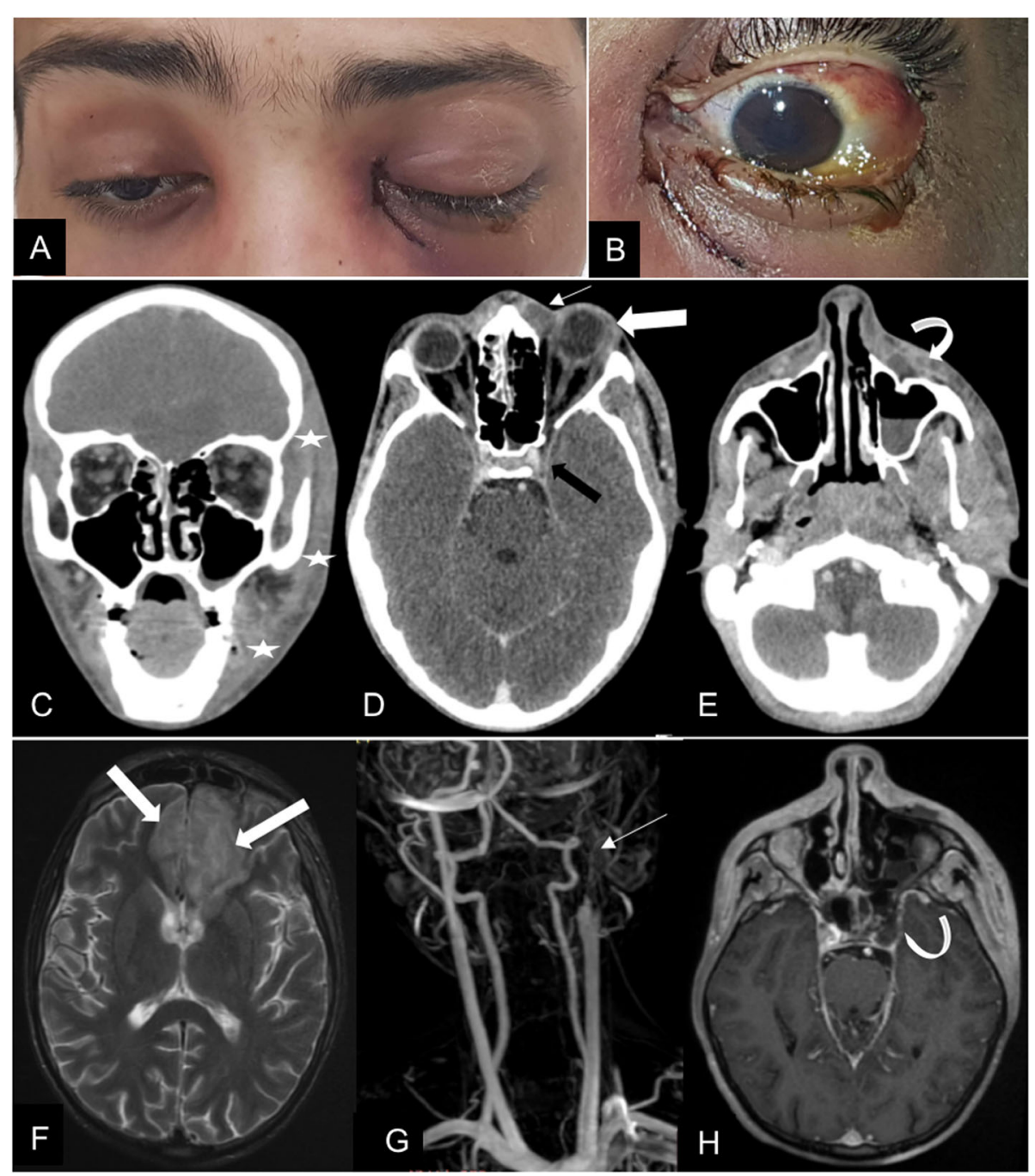

Fig. 1 A 20-year old COVID-19-affected patient presented with rhino-orbitocerebral mucormycosis. (A) Complete blepharoptosis and inflammatory signs are seen on the left side. There is a mild proptosis on the right side. (B) Note the conjunctival injection, the chemosis and the corneal oedema. (C) Coronal and (D, E) Axial contrast-enhanced brain CT scan show thickening with infiltration of left hemiface fat planes (white stars); left pre-septal collection (arrow) with exophthalmos and lengthening of the antero-posterior axis of the eyeball (large arrow). This collection reaches the cellulo-fatty tissues next to the left maxillary sinus (curved arrow), the latter is the site of a partial liquid filling. The left cavernous sinus shows signs of thrombosis (black arrow). (F) axial T2 weighted image MRI showing T2 hypersignals (large arrow) in areas of the frontal lobes confirming endocranial extension. (G) MR angiography shows left carotid artery thrombosis (arrow). (H) 3D T1 weighted sequence with contrast shows left cavernous sinus thrombosis (curved arrow) 


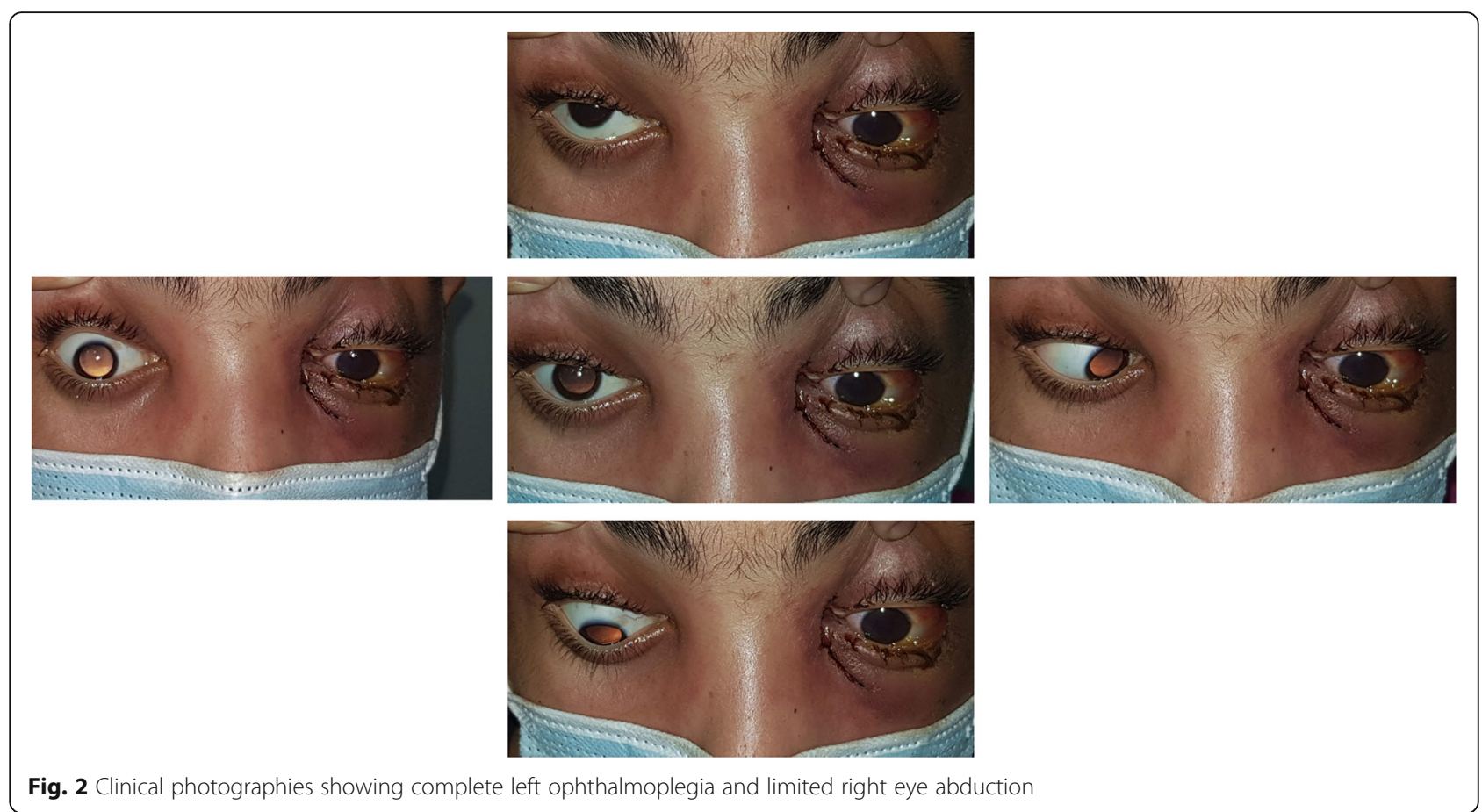

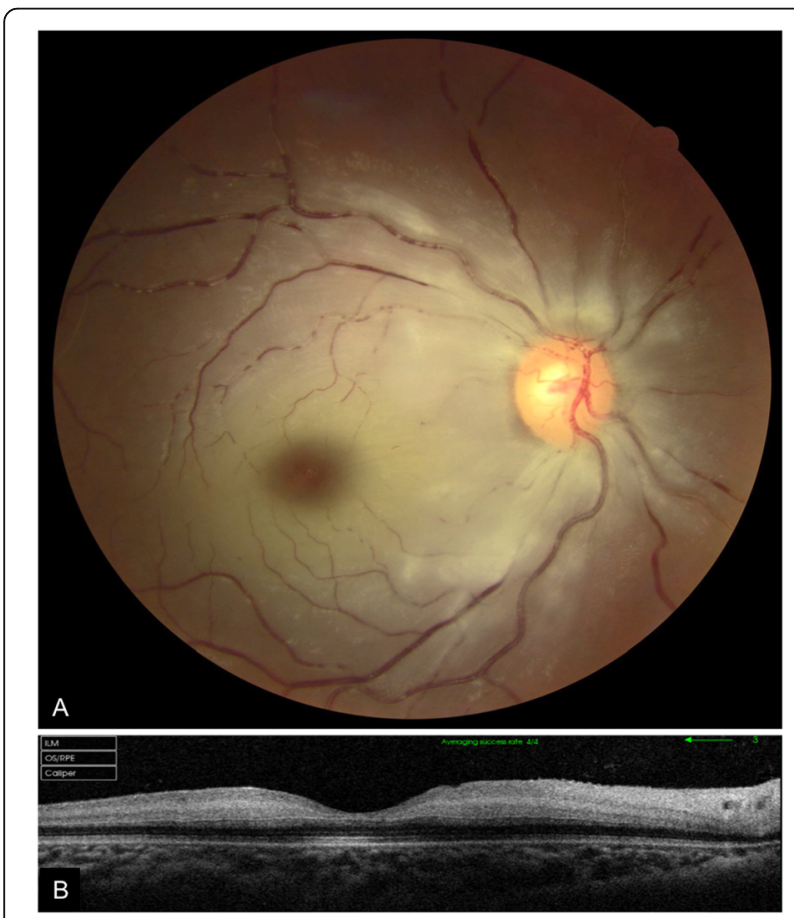

Fig. 3 (A) Fundus photography of the right eye showing retinal whitening with a cherry red spot and segmental blood flow consistent with central retinal artery occlusion. (B) Swept source OCT scan showing hyperreflectivity of inner retinal layers
The presentation of our patient suggests a left cavernous sinus and internal carotid thrombosis together with a right CRAO. From the ophthalmic and other orbital arteries, fungal infection advanced into the left cavernous sinus, ipsilateral carotid artery and right central retinal artery. This resulted in acute onset of bilateral vision loss and left ophthalmoplegia.

Successful treatment of ROCM highly depends on the early diagnosis of the infection, the control of the underlying predisposing factors and aggressive surgery [7].

Hence, Ophthalmologists should have a high index of suspicion for mucormycosis development in diabetic patients with COVID-19 illness, treated with corticosteroids. Vaccination against SARS-COv2 seems to be the best treatment to prevent COVID-19 and related blinding and fatal diseases.

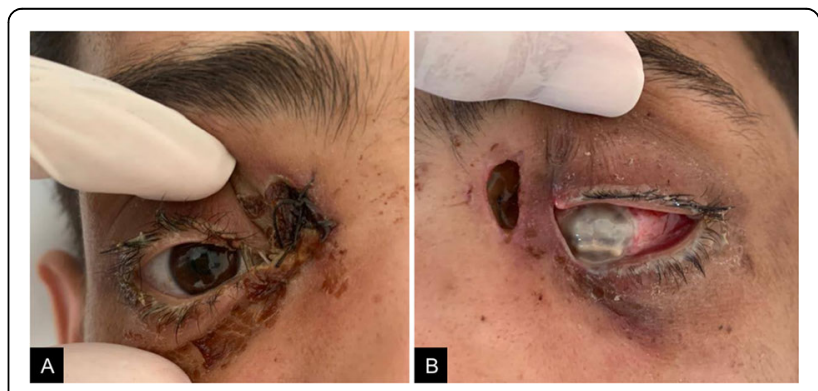

Fig. 4 Clinical photographies 12 days after initial presentation showing bilateral extensive eyelid necrosis with purulent melting of the left eyeball 


\section{Abbreviations}

ROCM: Rhino-Orbito-Cerebral Mucormycosis; CRAO: Central Retinal Artery Occlusion

\section{Acknowledgements}

$n / a$

\section{Authors' contributions}

IM writing/editing, JS writing/editing, RL editing, MB writing, MBS editing, MJ editing, MK writing/editing, LN editing. The author(s) read and approved the final manuscript.

\section{Funding}

We did not receive any funding.

Availability of data and materials

For data, please refer to corresponding author.

\section{Declarations}

\section{Ethics approval and consent to participate}

This brief report has been performed in accordance with the ethical standards as laid down in 1964 by the declaration of Helsinki and its later amendments. Anonymous case reports are approved by the ethics committee of our institution as long as written consent is obtained from the patients.

\section{Consent for publication}

Consent was signed by the patient.

\section{Competing interests}

No conflict of interest.

\section{Author details}

${ }^{1}$ A Department Hedi Raies Institute of Ophthalmology, Tunis El-Manar University, Tunis, Tunisie. ${ }^{2}$ Department of Oto-rhino-laryngology, Charles Nicoles Hospital, Tunis El-Manar University, Tunis, Tunisia. ${ }^{3}$ Department of Radiology, Charles Nicoles Hospital, Tunis El-Manar University, Tunis, Tunisia. ${ }^{4}$ Department of Ophthalmology, Fattouma Bourguiba University Hospital, Faculty of Medicine, University of Monastir, Monastir, Tunisia.

Received: 13 September 2021 Accepted: 4 October 2021 Published online: 18 October 2021

\section{References}

1. Sen, M., Honavar, S. G., Sharma, N., \& Sachdev, M. S. (2021). COVID19 and eye: a review of ophthalmic manifestations of COVID-19. Indian J Ophthalmol, 69(3), 488-509. https://doi.org/10.4103/ijo. IJO_ 297_21

2. Veisi, A., Bagheri, A., Eshaghi, M., Rikhtehgar, M. H., Rezaei Kanavi, M., \& Farjad, R. (2021). Rhino-orbital mucormycosis during steroid therapy in COVID-19 patients: a case report. European journal of ophthalmology, 11206721211009450. Advance online publication. https://doi.org/10.11 77/11206721211009450, 112067212110094

3. Eswaran, S., Balan, S. K., \& Saravanam, P. K. (2021). Acute fulminant Mucormycosis triggered by Covid 19 infection in a young patient. Indian journal of otolaryngology and head and neck surgery : official publication of the Association of Otolaryngologists of India, 1-5. Advance online publication. https://doi.org/10.1007/s12070-021-02 689-4

4. Mabrouki FZ, Sekhsoukh R, Aziouaz F, Mebrouk Y (2021) Acute blindness as a complication of severe acute respiratory syndrome Coronavirus-2. Cureus 13(8):e16857 https://doi.org/10.7759/cureus.16857

5. Cyr DG, Vicidomini CM, Siu NY, Elmann SE (2020) Severe bilateral vision loss in 2 patients with coronavirus disease 2019. J Neuroophthalmol 40(3):403405 https://doi.org/10.1097/WNO.0000000000001039

6. Atum, M., \& Demiryürek, B. E. (2021). Sudden bilateral vision loss in a COVID19 patient: a case report. Indian J Ophthalmol, 69(8), 2227-2228. https://doi. org/10.4103/ijo. IJO_3706_20

7. Honavar S. G. (2021). Code Mucor: guidelines for the diagnosis, staging and Management of Rhino-Orbito-Cerebral Mucormycosis in the setting of
COVID-19. Indian J Ophthalmol, 69(6), 1361-1365. https://doi.org/10.4103/ ijo. IJO_1165_21

\section{Publisher's Note}

Springer Nature remains neutral with regard to jurisdictional claims in published maps and institutional affiliations.

\section{Submit your manuscript to a SpringerOpen ${ }^{\circ}$ journal and benefit from:}

- Convenient online submission

- Rigorous peer review

- Open access: articles freely available online

- High visibility within the field

- Retaining the copyright to your article

Submit your next manuscript at $\boldsymbol{\nabla}$ springeropen.com 